\title{
Maize Seeds Submitted to Thermotherapy and Analyzed by Dynamic Speckle
}

\author{
Lucas Sacramoni Peixoto, Gisela Maiara Silva, Armando Kazuo Fujii, João José Dias Parisi, Rosa Helena Aguiar \\ and Juliana Aparecida Fracarolli \\ School of Agricultural Engineering, University of Campinas (UNICAMP), Av. Cândido Rondon, 501, Campinas 13083-875, SP, \\ Brazil
}

\begin{abstract}
The quality of the seeds used for sowing is fundamental for a high productivity and quality of the crop. Therefore, eradicating pathogens is essential for the plant to develop in the best possible way. The eradication of those pathogens can be accomplished by means of treatments that consist of the application of substances to the seeds or by performing physical procedures. Thermotherapy is a physical treatment, in which the seed is exposed to a given thermal energy, such as heated air or steam, and can be highly efficient for controlling those pathogens, in addition to reducing environmental damage and costs. The present work aimed to evaluate the efficiency of thermotherapy in two ways: wet heat (water) and dry heat (water vapor), both at $60^{\circ} \mathrm{C}$, alternating the exposure time to the thermal sources. The treatment with humid heat with a time of exposure of 5 min was the most efficient, since it presented higher germination percentages (83\%) and less occurrence of Fusarium sp. (33\%). It was observed that the most efficient thermotherapy is in the control of Fusarium, the most aggressive is for the quality of the seed. The quality of the treatments was evaluated through standard methodologies, according to the rules for seed analysis, such as germination and sanitation tests. Biospeckle laser was used to identify the microbial activity in these seeds, through activity maps generated by laser speckle contrast analysis (LASCA) processing. In this way, the research involving thermotherapy can be done by varying the temperature and the time of exposure to obtain values that considerably reduce the pathogenic agents and preserve the quality, in order to maintain the values of germination and vigor acceptable for commercialization.
\end{abstract}

Key words: Thermal treatment, wet heat, dry heat, Fusarium, germination.

\section{Introduction}

Maize propagation happens via its seed, which may be attacked by pathogenic agents. Among the pathogens which cause vegetable diseases and are transmitted via their seeds, fungi are highlighted, which besides diseases, also reduce the seeds' vigor and germination power [1].

Pathogenic fungi can be associated with maize seeds, causing physiological problems that may reduce the quality of these seeds, and these pathogens can be transmitted over long distances to the plant, affecting their development [2].

When the plant is contaminated with fungi or other pathogens, its development and productivity are

Corresponding author: Juliana Aparecida Fracarolli, assistant professor, research field: post-harvest technology. negatively affected, so it is necessary to use treatments to eradicate these microorganisms. Thus, treating the seed in order to eradicate pathogens becomes important, since the elimination of these agents will increase seed performance, directly influencing the plant's productivity [3].

In general, the control of diseases and pests in agriculture has increased in recent years and is usually carried out by the use of synthetic products, which have high costs and generate environmental and toxicological risks. As in plants, the control of seed diseases usually occurs through the use of chemical products $[4,5]$.

To receive the certificate of organic product, the seeds can neither be treated with toxic fungicides, nor use it in the plant already in development. In this way, the phytosanitary control with agrochemicals becomes 
a problem for companies or producers that want to obtain certification.

Infective inoculum of fungi in seeds can be eliminated with high efficiency through chemical, physical and biological treatments.

Thus, the commercial importance of maize crop and the importance of seed quality in productivity justify the efforts to identify alternative ways to treat these seeds and thus obtain a higher performance of the plants.

Procedures known as seed treatment are used for the control of pathogens. Those procedures aim to preserve or increase the seeds' performance, by controlling the negative effects of pathogens, in order to increase the productivity and development of a plant [3]. The treatments may be chemical (employment of substances, which will eliminate microorganisms), physical (such as thermotherapy, ozonation and electromagnetic radiations), biological (employment of bioprotectors, like Trichoderma) or a combination of them [3, 6-8].

Chemical treatments are the most common ones. Alternate treatments, like the physical one through thermotherapy and the biological one, may be used for phytosanitary control of seeds, reducing costs and environmental damages [5], allowing those seeds to be commercialized with a pesticide free and organic product label. Thermotherapy consists of exposing seeds to dry or wet heat. The combination of heat exposure temperature and treatment time has been assessed in several works [8-10].

Aiming to assess the sanitary quality of the seeds, non-destructive methods may be used, such as biospeckle. It is an interference optical phenomenon, which presents information about the analyzed surface, and it may be used to identify fungi and bacteria [11].

This research aimed to assess maize seeds submitted to thermotherapy via dry heat and humid heat in order to identify the most efficient one for the phytosanitary control of the seeds. The seeds were assessed through traditional methods and through biospeckle in order to identify the presence of microorganisms.

Biospeckle (or dynamic speckle) consists of an interference pattern that is formed when the light is dispersed over some active material, as is the case of vegetables [12]; this pattern of interference changes over time because the structures responsible for the scattering are active [13].

To obtain information on the activity of biological tissues through biospeckle, it is necessary to use image processing, which can generate visual results, such as the Fujii method, generalized differences and laser speckle contrast analysis (LASCA), or numerical results, such as moment of inertia (MI), among others.

\section{Materials and Methods}

\subsection{Initial Moisture, Germination and Sanitation} Assessment

The seeds used for the research were commercialized by the Agronomic Institute of Campinas (IAC), produced in the city of Campinas, São Paulo, Brazil, in a field of seed multiplication. The seeds are from a variety called IAC AIRAN, lot IA83, classified in size and shape in 20R sieve as round, category S2 that originates plants for the production of grains, harvested in September 2016 and used for the experiments in October 2016.

\subsubsection{Water Content}

The initial moisture of the seeds was determined according to the rules for the analysis of seeds, according to the oven method at $105^{\circ} \mathrm{C} \pm 3{ }^{\circ} \mathrm{C}$ for 24 $\mathrm{h}$ [14], in which three repetitions of approximately $2 \mathrm{~g}$ of seeds each were used. The results were expressed in average percentages, at wet basis.

\subsubsection{Sand Germination Test}

It was performed according to the rules for the analysis of seeds [14] by using four repetitions of 50 seeds. The seeds were placed in plastic boxes $(30.0 \times$ $30.0 \times 5.0 \mathrm{~cm}^{3}$ ) on dampened sand substrate with $60 \%$ of the holding capacity of that sand and kept at $30^{\circ} \mathrm{C}$. The results were submitted to analysis of variance by 
$F$ test and the treatment means were compared by Tukey test at 5\% probability using the Sisvar 5.3 program.

\subsubsection{Sanitation Test}

The method was consisted of the distribution of eight repetitions of 25 seeds on paper filter dampened with distilled water in plastic trays. Before being placed at $20^{\circ} \mathrm{C} \pm 2{ }^{\circ} \mathrm{C}$, under intermittent regimen of $12 \mathrm{~h}$ of light/12 $\mathrm{h}$ of darkness, the seeds remained immersed in distilled water for $12 \mathrm{~h}$ in order to increase the moisture, making the subsequent freezing easier ( $24 \mathrm{~h}$ in a freezer at $-20^{\circ} \mathrm{C}$ ). By this test, it was possible to verify the presence of Fusarium sp.. The results were submitted to analysis of variance by $F$ test and the treatment means were compared by Tukey test at 5\% probability using the Sisvar 5.3 program.

\subsection{Treatments}

\subsubsection{Thermotherapy via Wet Heat}

The seeds were placed in net bags, which were randomly put in a beaker with water heated at $60^{\circ} \mathrm{C}$ in the proportion of weight of seeds and water of 1:6.

Two treatments were performed with the wet heat, seeds which remained for $5 \mathrm{~min}$ and for $20 \mathrm{~min}$ in contact with the thermal source.

\subsubsection{Thermotherapy via Dry Heat}

The seeds were placed in kraft paper bags and placed in oven with air circulation at $60{ }^{\circ} \mathrm{C}$, where they remained for $3 \mathrm{~d}$ and $10 \mathrm{~d}$, thus defining another two treatments.

\subsection{Assessment Tests}

\subsubsection{Modified Cold Test}

The cold test was carried out complying with the recommendations of Ref. [15]. Each one of the four repetitions of 50 seeds of each treatment was placed inside three sheets of paper towel ("germitest"), dampened in water, equivalent to 2.5 times the mass of the dry paper. Then, the paper rolls were kept at $10^{\circ} \mathrm{C}$ for $7 \mathrm{~d}$ in biochemical oxygen demand (BOD) chamber. The results were submitted to analysis of variance by $F$ test and the treatment means were compared by Tukey test at $5 \%$ probability using the Sisvar 5.3 program.

\subsubsection{Biospeckle}

It was used in the optical trials: a red diode laser of $632 \mathrm{~nm}$ of wavelength and $10 \mathrm{~mW}$ of power, a Canon Rebel T6 EOS 1300D digital camera, a computer with software for image processing and for statistical treatment. For the image processing, the software Matlab and ImageJ version 1.50i were used [16]. For the statistical treatment, the software Sisvar version 5.6 was used [17].

Ten repetitions were performed for each treatment, one seed per repetition. After processing the photographs of the seeds with the LASCA algorithm [18], the activity map of the 10 seeds of the five treatments was obtained. With the biospeckle, it was possible to identify activity in the seed tissue, which was attributed to fungi activity, since all evaluated seeds were frozen and killed before analysis. In the seeds in which activity was identified, this was attributed to the Fusarium species, being the fungus that most occurred in the sanity test. Biospeckle was not used to differentiate fungal species in this experiment.

From the activity map, histograms were obtained, indicating the average value for each map of the levels, where level 0 represented the highest value of biological activity and level 255, the lowest biological activity. The average value of color results was submitted to analysis of variance by $F$ test and the treatment means were compared by Tukey test at $5 \%$ probability using the Sisvar 5.3 program.

\section{Results and Discussion}

The initial acquired seed quality assessment presented the results: the moisture content was $10.5 \%$, the germination was $93.5 \%$ and the occurrence of Fusarium sp. was $97.5 \%$ in the sanitation test [14].

Fig. 1 shows the results referring to the germination test, where NT refers to seeds with no treatment, TH-1 


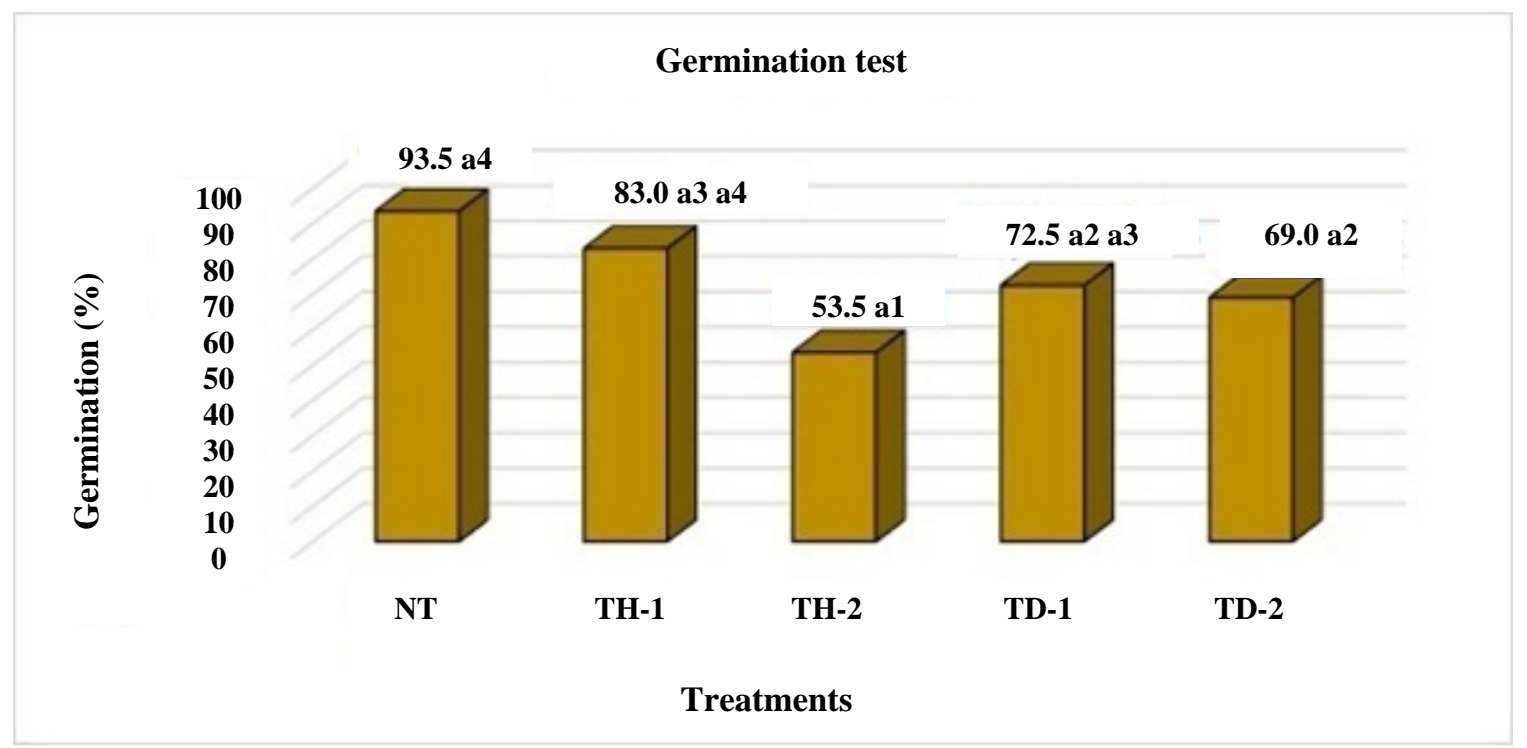

Fig. 1 Results of average germination for the four assessed treatments and also for the samples with no treatment.

The averages followed by the same letter and number in each treatment do not statistically differ among themselves, through Tukey test at $5 \%$ probability.

NT: seeds with no treatment; TH-1: treatment with thermotherapy via humid heat with 5 min of exposure; TH-2: treatment with thermotherapy via humid heat with 20 min of exposure; TD-1: treatment with thermotherapy via dry heat and $3 \mathrm{~d}$ of exposure; TD-2: treatment with thermotherapy via dry heat and $10 \mathrm{~d}$ of exposure.

is the treatment with thermotherapy via humid heat with 5 min of exposure, TH-2 is the treatment with thermotherapy via humid heat with 20 min of exposure, TD- 1 is the treatment with thermotherapy via dry heat and $3 \mathrm{~d}$ of exposure, and TD-2 is the treatment with thermotherapy via dry heat and $10 \mathrm{~d}$ of exposure.

It was possible to observe that all treatments with thermotherapy reduced the germination when compared to the samples with no treatment, which had 93.5\% of germination. That happened because thermotherapy may be lethal under the physiological point of view, making the seeds unviable depending on how aggressive the heat exposure is.

Comparing treatments $\mathrm{TH}-1$ to $\mathrm{TH}-2$ and TD-1 to $\mathrm{TD}-2$, it is possible to conclude that the longer the exposure time to a certain amount of thermal energy, the lower the germination rate is, that is, the more aggressive the treatment is to the seed.

Thermotherapy via humid heat presented a higher germination variation (29.5\%) between treatments TH-1 and TH-2, while thermotherapy via dry heat, a variation of only 3.5\% between TD-1 and TD-2. That shows that the thermotherapy with heated water is more aggressive to the seeds. Even being more aggressive to the seeds, the use of humid heat with 5 min of exposure presented $83 \%$ of germination, the highest one in all treatments.

The treatment with humid heat for $20 \mathrm{~min}$ (TH-2) was the most aggressive, presenting germination of $53.5 \%$.

Fig. 2 presents the data referring to the cold test, which indicates the capability of the seeds, referring to each treatment, to germinate in adverse temperature conditions.

It is observed that the seed germination in low temperature was inferior to the germination in ideal conditions. The samples referring to the seeds with no treatment had $66 \%$ of germination and, as indicated on initial tests, the samples put to germinate in ideal conditions had $93.5 \%$ of germination.

There was great reduction in germination when the seed exposure was increased from $5 \mathrm{~min}$ to $20 \mathrm{~min}$ in heated water, a similar behavior to what occurred with 


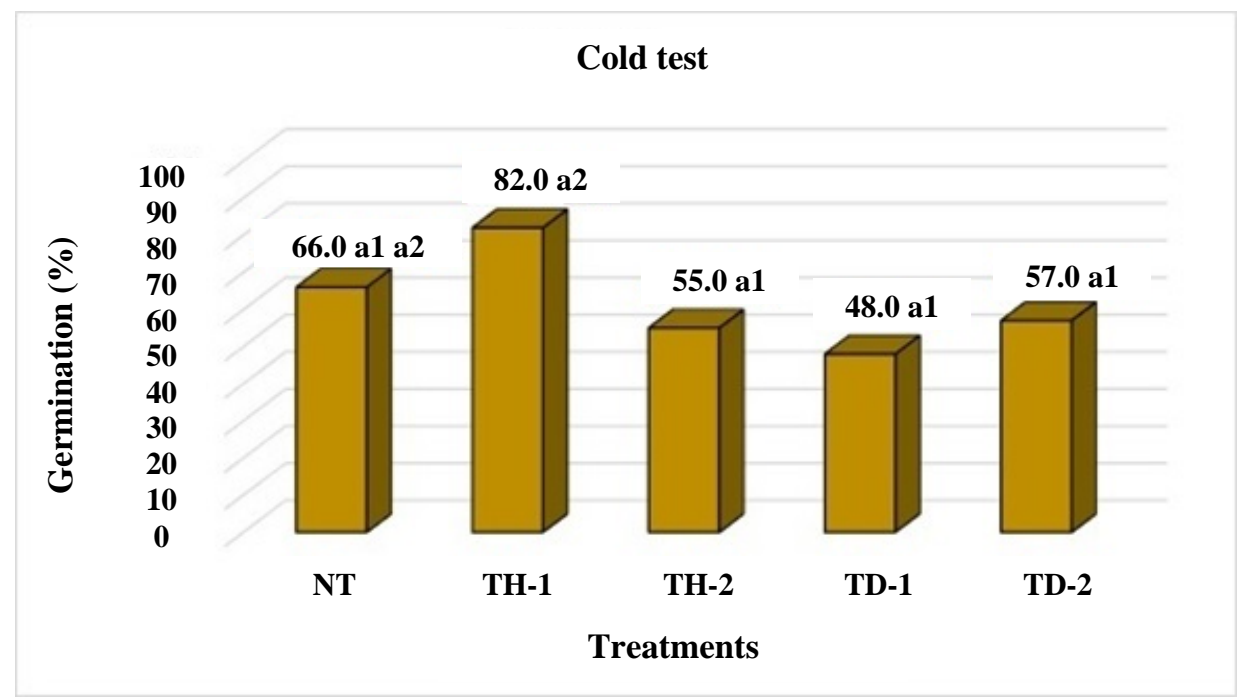

Fig. 2 Results of average germination for the four assessed treatments and also for the samples with no treatment, submitted to the cold test.

The averages followed by the same letter and number in each treatment do not statistically differ among themselves, through Tukey test at $5 \%$ probability.

NT: seeds with no treatment; TH-1: treatment with thermotherapy via humid heat with 5 min of exposure; TH-2: treatment with thermotherapy via humid heat with 20 min of exposure; TD-1: treatment with thermotherapy via dry heat and $3 \mathrm{~d}$ of exposure; TD-2: treatment with thermotherapy via dry heat and $10 \mathrm{~d}$ of exposure.

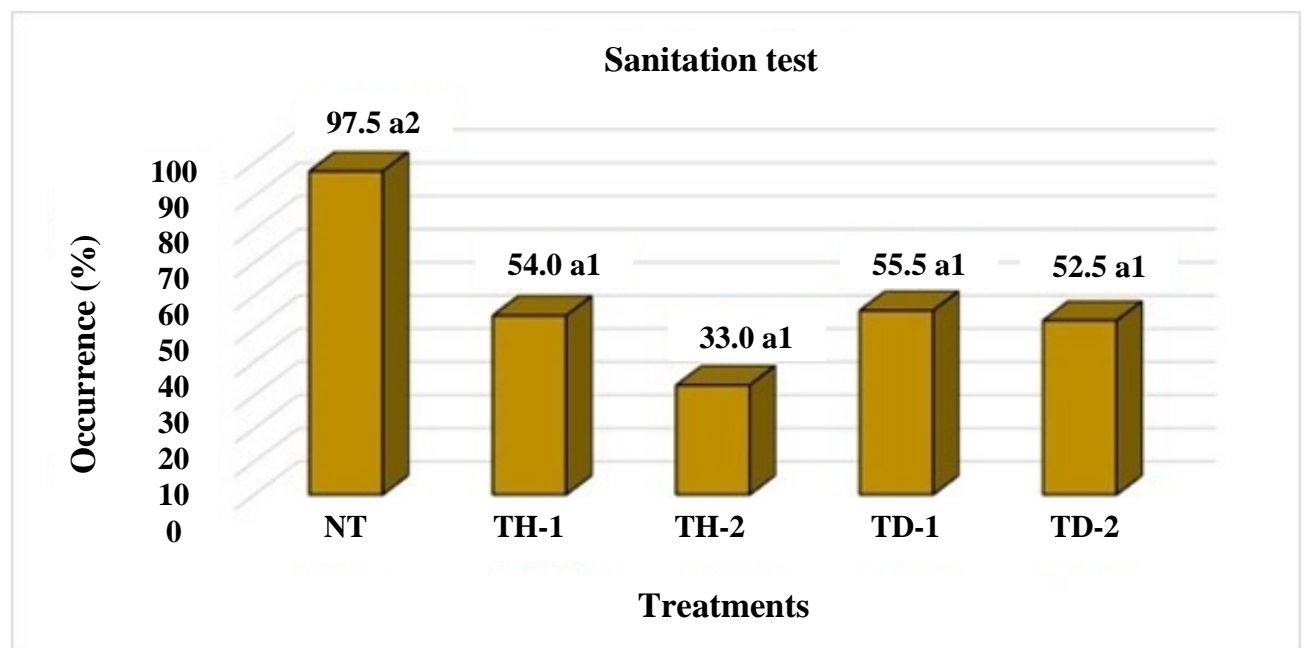

Fig. 3 Occurrence of Fusarium sp. for the four assessed treatments and also for the samples with no treatment, submitted to the sanitation test.

The averages followed by the same letter and number in each treatment do not statistically differ among themselves, through Tukey test at $5 \%$ probability.

NT: seeds with no treatment; TH-1: treatment with thermotherapy via humid heat with 5 min of exposure; TH-2: treatment with thermotherapy via humid heat with 20 min of exposure; TD-1: treatment with thermotherapy via dry heat and $3 \mathrm{~d}$ of exposure; TD-2: treatment with thermotherapy via dry heat and $10 \mathrm{~d}$ of exposure.

the germination test.

Fig. 3 shows the occurrence in percentage of Fusarium sp. in the four treatments and also for the samples with no treatment. Only the counting of
Fusarium sp. was performed, for it is the main storage fungus which attacks maize seeds.

The occurrence in the samples with no treatment was of $97.5 \%$, much higher than the occurrence of the 


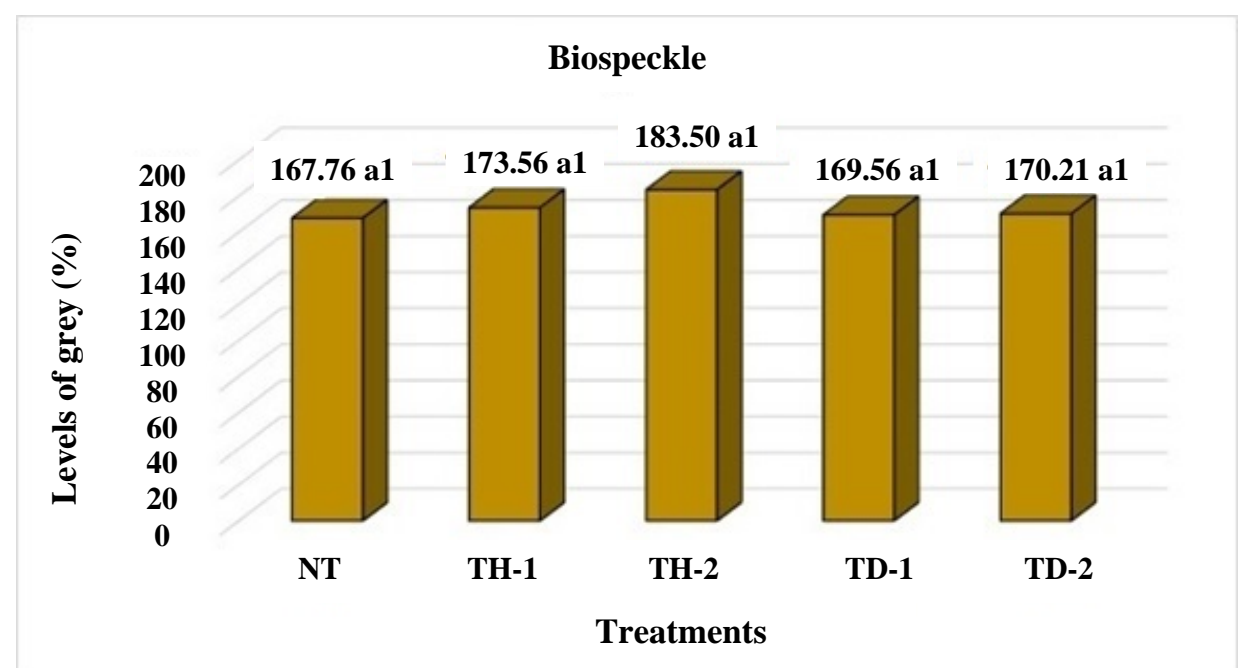

Fig. 4 Levels for the four treatments and also for the samples with no treatment, submitted to optical analysis through biospeckle.

The averages followed by the same letter and number in each treatment do not statistically differ among themselves, through Tukey test at $5 \%$ probability.

NT: seeds with no treatment; TH-1: treatment with thermotherapy via humid heat with 5 min of exposure; TH-2: treatment with thermotherapy via humid heat with 20 min of exposure; TD-1: treatment with thermotherapy via dry heat and $3 \mathrm{~d}$ of exposure; TD-2: treatment with thermotherapy via dry heat and $10 \mathrm{~d}$ of exposure.

samples submitted to thermotherapy. That indicates that thermotherapy can be used for the phytosanitary control of maize seeds.

Treatments TH-1, TD-1 and TD-2 presented the occurrence of Fusarium sp. very close to one another. Increasing the exposure time to dry heat from $3 \mathrm{~d}$ to $10 \mathrm{~d}$ did not significantly reduce the occurrence of Fusarium sp..

The greatest reduction of occurrence of Fusarium sp. happened in treatment TH-2, that is, the treatment which affected germination and vigor the most was the most efficient on the control of Fusarium. That shows that the more lethal the thermal treatment is for the pathogens, the more lethal it is for the seeds.

From the activity maps obtained with the LASCA processing [18], the histograms with the levels ( 0 to 255) were obtained.

Fig. 4 presented the average of those levels, obtained from the histograms, where it may be observed that treatments TH-1, TD- 1 and TD-2 presented very similar averages. Like the averages from the sanitation test (Fig. 3), the samples with no treatment showed the lowest average of level of gray and the highest occurrence of Fusarium sp., and treatment TH-2 showed the highest value of level of gray and the lowest occurrence of Fusarium sp.. That is, the seeds with higher biological activity due to the presence of fungi presented lower levels of gray, and the seeds with lower incidence of fungi presented higher levels of gray. The levels of gray on the images obtained through LASCA indicated higher or lower biological activity.

\section{Conclusions}

Thermotherapy damages the seeds by exposing them to a thermal energy source, reducing the vigor and germination percentage, but it reduces the occurrence of Fusarium sp., which is the main storage fungus in maize seeds.

The thermal treatment via humid heat is the most aggressive to the seeds, reducing germination and vigor in a more significant way, except for treatment TH-1, which may be related to the short exposure time (5 min).

Although it seems less efficient for the control of Fusarium sp., thermotherapy via dry heat is less 
aggressive to the quality of the seeds.

Analyzing the four treatments (TH-1, TH-2, TD-1 and TD-2), the treatment with humid heat with a 5 min exposure time (TH-1) was the most efficient, since it showed higher percentages of germination (83.0\%, Fig 1) and low occurrence of Fusarium sp. (54.0\%, Fig 3).

It was observed that the more efficient thermotherapy is on the control of Fusarium, the more aggressive it is to the seed quality. So, future works should attempt to alternate temperatures and exposure times in order to find values, where there is a larger difference between the lethal point for the seeds and the lethal point for the fungi.

Biospeckle through the LASCA technique was efficient on the identification of the highest or lowest occurrence of Fusarium sp. in the maize seeds.

\section{References}

[1] Machado, J. C. 1994. "Pathogen Tolerance Patterns Associated with Seeds.” Annu. Plant Pathol. Rev. 2: 229-63.

[2] Coutinho, W. M., Silva-Mann, R., Vieira, M. G. G. C., Machado, C. F., and Machado, J. C. 2007. "Sanitary and Physiological Quality of Maize Seeds Submitted to Thermotherapy and Physiological Conditioning.” Fitopatol. Bras. 32: 458-64. doi:10.1590/S0100-41582007000600002. (in Portuguese)

[3] Menten, J. O. M. 1991. Seed Pathogens: Detection, Damage and Chemical Control. Piracicaba: ESALQ/FEALQ, 321. https://books.google.com.br/ books?id=aSFvygAACAAJ. (in Portuguese)

[4] Lima, H. F., Bruno, R. L. A., Bruno, G. B., and Bandeira, I. S. A. 1999. "Evaluation of Alternative Products in the Control of Pests and the Physiological Quality of Macassar Bean Seeds Stored.” Rev. Bras. Eng. Agríc. E Ambient. 3: 49-53. doi:10.1590/1807-1929/agriambi. v3n1p49-53. (in Portuguese)

[5] Coutinho, W. M., Araújo, E., and Magalhães, F. H. L. 1999. "Effects of Extracts of Anacardiaceous Plants and Chemical Fungicides Benomyl and Captan on Microflora and Physiological Quality of Bean Seeds (Phaseolus vulgaris L.).” Sci. Agrotechnology 23: 560-8.

[6] Babadoost, M., Derie, M. L., and Gabrielson, R. L. 1996.
"Efficacy of Sodium Hypochlorite Treatments for Control of Xanthomonas campestris pv. campestris in Brassica Seeds.” Seed Sci. Technol. 24: 7-15.

[7] Prohens, J., Soler, S., and Nuez, F. 1999. "The Effects of Thermotherapy and Sodium Hypochlorite Treatments on Pepino Seed Germination, a Crucial Step in Breeding Programmes.” Ann. Appl. Biol. 134: 299-305. doi:10.1111/j.1744-7348.1999.tb05268.x.

[8] Machado, J. C. 2000. Treatment of Seeds in Disease Control. Lavras: UFLA.

[9] Bergman, S. 1994. "Hot Treatment of Seed-Borne Fungi on Cereals.” Seed Pathol. Microbiol. 5: 20-1.

[10] Trigo, M. F. O., Pierobom, C. R., Nedel, J. L., and Trigo, L. F. N. 1998. "Heat Treatment in Carrot Seeds.” Brazilian Agricultural Research 33: 357-61. (in Portuguese)

[11] Murialdo, S. E., Passoni, L. I., Guzman, M. N., Sendra, G. H., Rabal, H., Trivi, M., and Gonzalez, J. F. 2012. "Discrimination of Motile Bacteria from Filamentous Fungi Using Dynamic Speckle.” J. Biomed. Opt. 17 (5): 056011. doi:10.1117/1.JBO.17.5.056011.

[12] Dainty, J. C., ed.. 1984. Laser Speckle and Related Phenomena. 2nd ed.. Berlin, New York: Springer-Verlag.

[13] Alves, J. A., Braga, R. A., and Vilas Boas, E. V. B. 2013. "Identification of Respiration Rate and Water Activity Change in Fresh-Cut Carrots Using Biospeckle Laser and Frequency Approach.” Postharvest Biol. Technol. 86: 381-6. doi:10.1016/j.postharvbio.2013.07.030.

[14] Brazil. 2009. Ministry of Agriculture, Livestock and Supply, Secretariat of Agricultural Defense. Rules for Seed Analysis. Brasília: MAPA/ACS, 395. http://www.bs.cca.ufsc.br/publicacoes/regras\%20analise \%20sementes.pdf. (in Portuguese)

[15] Barros, A. S. R., Lima Dias, M. C. L., Cicero, S. M., and Krzyzanowski, F. C. 1999. “Cold Test. Chp. 5.” In Seed Vigor: Concepts and Tests, edited by Krzyzanowski, F. C., Vieira, R. D., and França Neto, J. B. Londrina, PR, Brazil: Abrates, 1-15. (in Portuguese)

[16] Schneider, C. A., Rasband, W. S., and Eliceiri, K. W. 2012. "NIH Image to ImageJ: 25 Years of Image Analysis.” Nat. Methods 9: 671-5. doi:10.1038/nmeth.2089.

[17] Ferreira, D. F. 2014. "Sisvar: A Guide for Its Bootstrap Procedures in Multiple Comparisons.” Ciênc. e Agrotecnologia 38: 109-12. doi:10.1590/S141370542014000200001.

[18] Briers, J. D. 1996. "Laser Speckle Contrast Analysis (LASCA): A Non-scanning, Full-Field Technique for Monitoring Capillary Blood Flow.” J. Biomed. Opt. 1 (2): 174-9. doi:10.1117/12.231359. 